NASA/TM-2012-217622

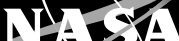

\title{
Investigation of a Moiré Based Crack Detection Technique for Propulsion Health Monitoring
}

Mark R. Woike, Ali Abdul-Aziz, Gustave C. Fralick, and John D. Wrbanek

Glenn Research Center, Cleveland, Ohio 


\section{NASA STI Program . . . in Profile}

Since its founding, NASA has been dedicated to the advancement of aeronautics and space science. The NASA Scientific and Technical Information (STI) program plays a key part in helping NASA maintain this important role.

The NASA STI Program operates under the auspices of the Agency Chief Information Officer. It collects, organizes, provides for archiving, and disseminates NASA's STI. The NASA STI program provides access to the NASA Aeronautics and Space Database and its public interface, the NASA Technical Reports Server, thus providing one of the largest collections of aeronautical and space science STI in the world. Results are published in both non-NASA channels and by NASA in the NASA STI Report Series, which includes the following report types:

- TECHNICAL PUBLICATION. Reports of completed research or a major significant phase of research that present the results of NASA programs and include extensive data or theoretical analysis. Includes compilations of significant scientific and technical data and information deemed to be of continuing reference value. NASA counterpart of peer-reviewed formal professional papers but has less stringent limitations on manuscript length and extent of graphic presentations.

- TECHNICAL MEMORANDUM. Scientific and technical findings that are preliminary or of specialized interest, e.g., quick release reports, working papers, and bibliographies that contain minimal annotation. Does not contain extensive analysis.

- CONTRACTOR REPORT. Scientific and technical findings by NASA-sponsored contractors and grantees.
- CONFERENCE PUBLICATION. Collected papers from scientific and technical conferences, symposia, seminars, or other meetings sponsored or cosponsored by NASA.

- SPECIAL PUBLICATION. Scientific, technical, or historical information from NASA programs, projects, and missions, often concerned with subjects having substantial public interest.

- TECHNICAL TRANSLATION. Englishlanguage translations of foreign scientific and technical material pertinent to NASA's mission.

Specialized services also include creating custom thesauri, building customized databases, organizing and publishing research results.

For more information about the NASA STI program, see the following:

- Access the NASA STI program home page at http://www.sti.nasa.gov

- E-mail your question to help@sti.nasa.gov

- Fax your question to the NASA STI Information Desk at 443-757-5803

- Phone the NASA STI Information Desk at 443-757-5802

- Write to: STI Information Desk NASA Center for AeroSpace Information 7115 Standard Drive Hanover, MD 21076-1320 
NASA/TM-2012-217622

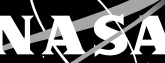

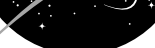

\section{Investigation of a Moiré Based Crack Detection Technique for Propulsion Health Monitoring}

Mark R. Woike, Ali Abdul-Aziz, Gustave C. Fralick, and John D. Wrbanek

Glenn Research Center, Cleveland, Ohio

Prepared for the

SMART Structures and Materials and Nondestructive Evaluation and Health Monitoring 2012

sponsored by the International Society for Optical Engineering (SPIE)

San Diego, California, March 11-15, 2012

National Aeronautics and

Space Administration

Glenn Research Center

Cleveland, Ohio 44135 


\section{Acknowledgments}

The authors would like to acknowledge and thank Timothy Bencic of the Glenn Research Center's Optical Instrumentation Branch for the use of the camera, high power light emitting diode (LED) and conditioning electronics used in the experiment; Timothy Heineke of the Glenn Research Center's Machining Branch for the precision machining of the circular patterns on the subscale engine disk; and the NASA Aviation Safety Program’s (AvSP) Vehicle Systems Safety Technologies (VSST) Project for supporting this research effort.

This report contains preliminary findings, subject to revision as analysis proceeds.

Trade names and trademarks are used in this report for identification only. Their usage does not constitute an official endorsement, either expressed or implied, by the National Aeronautics and Space Administration.

Level of Review: This material has been technically reviewed by technical management.

Available from

NASA Center for Aerospace Information 7115 Standard Drive

Hanover, MD 21076-1320
National Technical Information Service 5301 Shawnee Road Alexandria, VA 22312 


\title{
Investigation of a Moiré Based Crack Detection Technique for Propulsion Health Monitoring
}

\author{
Mark R. Woike, Ali Abdul-Aziz, Gustave C. Fralick, and John D. Wrbanek \\ National Aeronautics and Space Administration \\ Glenn Research Center \\ Cleveland, Ohio 44135
}

\begin{abstract}
The development of techniques for the health monitoring of the rotating components in gas turbine engines is of major interest to NASA's Aviation Safety Program. As part of this on-going effort several experiments utilizing a novel optical Moiré based concept along with external blade tip clearance and shaft displacement instrumentation were conducted on a simulated turbine engine disk as a means of demonstrating a potential optical crack detection technique. A Moiré pattern results from the overlap of two repetitive patterns with slightly different periods. With this technique, it is possible to detect very small differences in spacing and hence radial growth in a rotating disk due to a flaw such as a crack. The experiment involved etching a circular reference pattern on a subscale engine disk that had a $50.8 \mathrm{~mm}$ ( 2 in.) long notch machined into it to simulate a crack. The disk was operated at speeds up to $12000 \mathrm{rpm}$ and the Moiré pattern due to the shift with respect to the reference pattern was monitored as a means of detecting the radial growth of the disk due to the defect. In addition, blade displacement data were acquired using external blade tip clearance and shaft displacement sensors as a means of confirming the data obtained from the optical technique. The results of the crack detection experiments and its associated analysis are presented in this paper.
\end{abstract}

\section{Introduction}

One of the primary focus areas being investigated under NASA's Aviation Safety Program's (AvSP) Vehicle Systems Safety Technologies (VSST) Project is the development of new fault-detection and structural health monitoring techniques for gas turbine engines. The rotating components of modern gas turbine engines operate in severe conditions and are exposed to high thermal and mechanical loads. The cumulative effects of these loads can lead to high stresses, structural deformities, cracks, and eventual component failure. Current detection practices involve periodic inspections and schedule-based maintenance of engine components to ensure their integrity over the lifetime of the engine. However, these methods have their limitations, and failures are experienced leading to unscheduled maintenance and unplanned engine shutdowns. To prevent these failures and enhance aviation safety, the NASA Glenn Research Center as part of the overall AvSP's VSST Project is investigating new types of sensor technologies and techniques for the in-situ structural health monitoring and detection of flaws in gas turbine engines.

Over the last several years research has been conducted in the NASA Glenn Research Center's Rotor Dynamics Laboratory to develop both global and local approaches for monitoring critical rotor components (Refs. 1 to 8). The Rotordynamics Laboratory consists of a high-precision spin rig that can rotate subscale engine disks at speeds up to $12000 \mathrm{rpm}$. The rig provides a low-cost venue for developing and validating lower Technology Readiness Level (TRL) structural health monitoring schemes prior to implementing them on more expensive and complicated engine hardware. This investigation was to determine if an optical technique based on the Moiré principal could be used to observe localized radial growth due to high stresses caused by an anomaly such as a crack in a rotating disk. The experiment involved machining a circular reference pattern on a subscale engine disk that had a $50.8 \mathrm{~mm}(2 \mathrm{in}$.) long notch machined into it to simulate a crack. The disk was operated at speeds up to $12000 \mathrm{rpm}$ and the Moiré pattern due to the shift with respect to the reference pattern was monitored as a means of detecting 
the localized radial growth of the disk due to the defect. In addition, blade displacement data sets were acquired using external blade tip clearance and shaft displacement sensors for comparison to the optical data and to further develop fault detection techniques associated with these technologies. The theory behind the Moiré based crack detection scheme, the experimental setup, and the experimental results are presented in this paper.

\section{Theory and Technical Approach}

\section{Basic Theory}

Moiré patterns are quite common in everyday occurrences and result from the overlap of figures with periodic spacing (Refs. 9 and 10). For this experiment it was desired to use the geometrical relationship associated with Moiré patterns as a means of non-intrusively optically measuring localized radial growth or strain in a rotating disk. The concept behind this technique is as follows.

Figure 1 shows the overlap of two vertical patterns. The first pattern has a vertical line spacing of $p$, while the second pattern has been "stretched" and has a vertical line spacing of $q$, which is related to $p$ by the following equation:

$$
\begin{aligned}
& q=p+\Delta p, \\
& 0<\Delta<1
\end{aligned}
$$

If the patterns are lined up starting on the left side, the shift increases going to the right. Initially the lines of the patterns coincide and match up. This represents a light zone. After a given number of lines, the lines of the second pattern fall between the lines of the first. This represents a dark zone. This appearance alternates depending on whether the lines coincide (light zone) or are opposed (dark zone). The middle of the first dark zone is when shift in spacing between the first and second pattern is $p / 2$. The $\mathrm{n}^{\text {th }}$ line of the second pattern is shifted by $\mathrm{n} \cdot \Delta p$ when compared to the $\mathrm{n}^{\text {th }}$ line of the first. Thus, at the middle of the first dark zone the following relationships can be established:

$$
\begin{gathered}
n \Delta p=\frac{p}{2} \\
n=p /(2 \Delta p)
\end{gathered}
$$

Where $n$ in Equation (3) is the number of lines on the second pattern that it takes to get to the middle of the dark zone. The distance, $D$, between the initial start point; the middle of a light zone, and the middle of the dark zone is then defined by the following:

$$
D=n(p+\Delta p)
$$

Substituting Equation (3) for $n$ at this point yields:

$$
D=\frac{p^{2}}{2 \Delta p}+\frac{p}{2}
$$




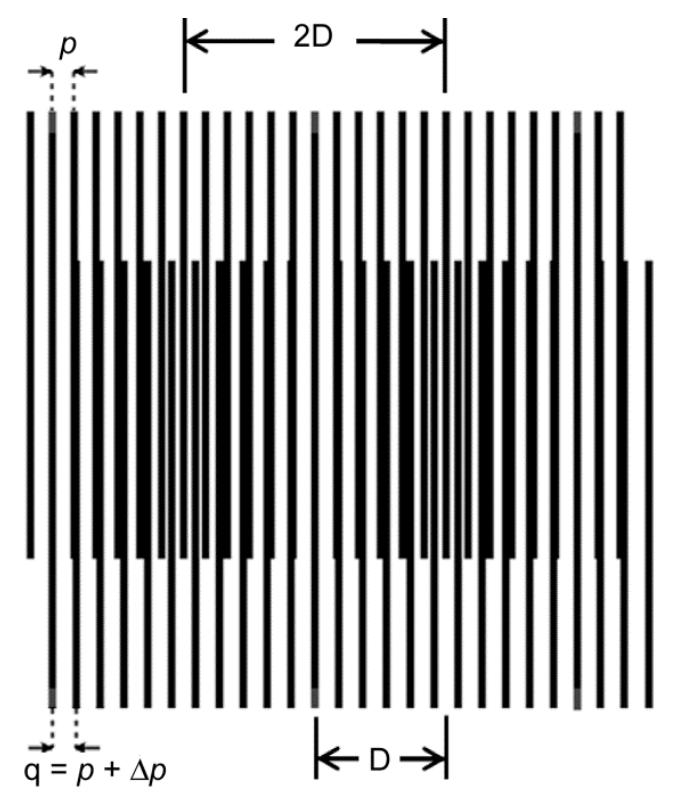

Figure 1.-Example of a Moiré pattern.

The distance between two dark zones or two light zones would be 2D. Finally, rearranging Equation (5) to solve for $\Delta p$ yields the following:

$$
\Delta p=\frac{p^{2}}{(2 \mathrm{D}-p)}
$$

If the first pattern is as a baseline image of a test article in its initial state and the second pattern is obtained while the article is being loaded or stretched. Strain, $\varepsilon$, the test article is undergoing would be given by the following equations:

$$
\begin{gathered}
\varepsilon=\frac{\Delta p}{p} \\
\varepsilon=\frac{p}{(2 \mathrm{D}-p)}
\end{gathered}
$$

Thus, by knowing the initial line spacing, $p$, and optically observing the distance between two dark zones or two light zones, 2D, or the distance between a light and dark zone, $D$, the difference in spacing, $\Delta p$, and hence strain, $\varepsilon$, can be calculated.

\section{Technical Approach}

The Moiré effect amplifies small changes and has the potential to make these changes optically measureable by observing the spacing between the dark or light zones of two patterns overlaid on each other. This characteristic is the basis of the experiment to measure radial growth or strain on a rotating disk due to high stresses caused by operation or an anomaly such as a crack. Figure 2 shows the overall concept behind the experiment. The technical approach was to apply a pattern of concentric equally 


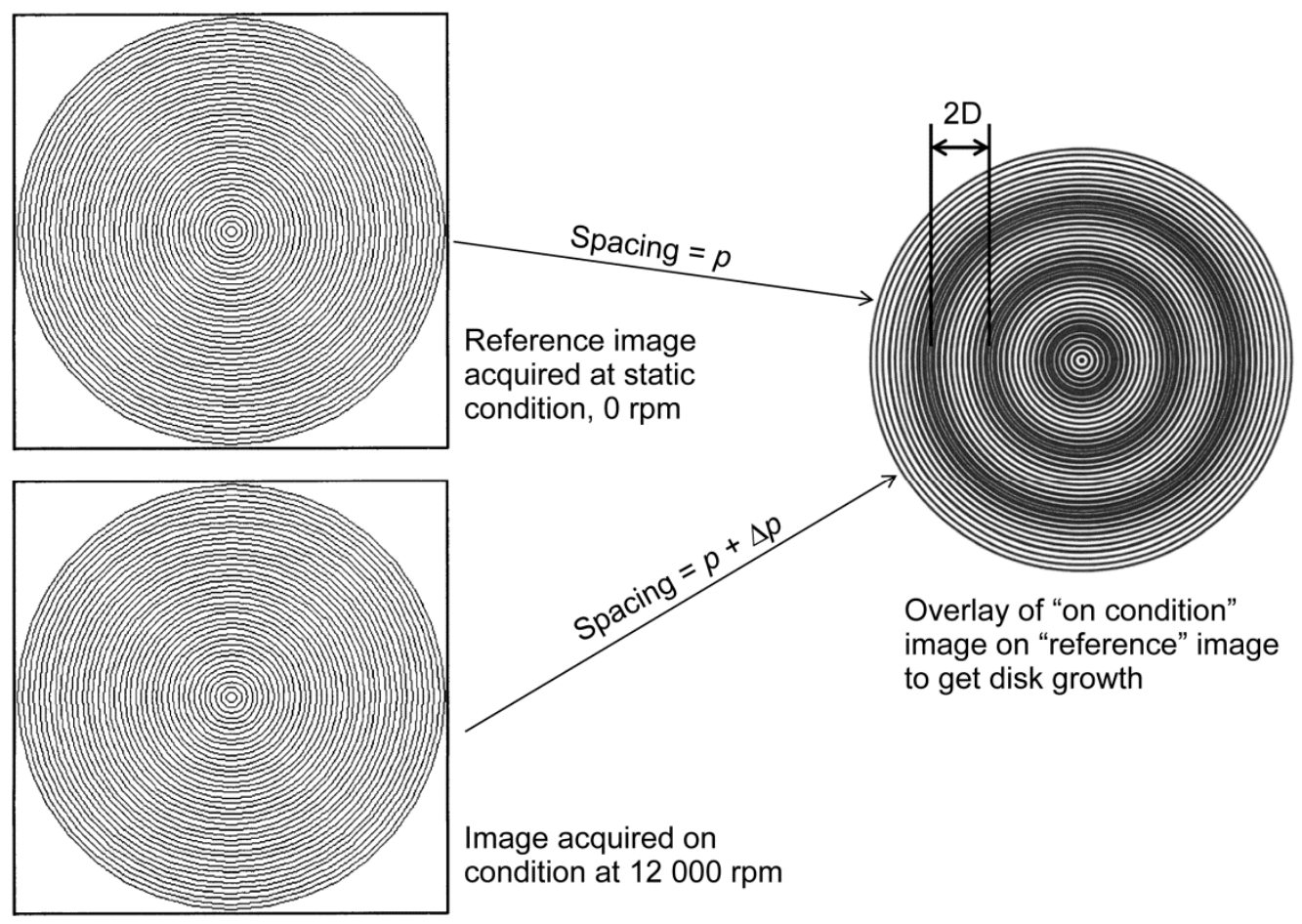

Figure 2.-Moiré concept applied to a rotating disk.

spaced rings at a known spacing on a subscale turbine engine disk and acquire images of it at both static, $0 \mathrm{rpm}$, and at a loaded condition of $12000 \mathrm{rpm}$. The image that was taken on-condition was then overlaid on the static reference image using image processing software. Registration marks that were placed on the disk were used for sub-pixel alignment. The composite image was then analyzed for the appearance of the dark and light zones due to the radial growth of the disk. Measuring the distance between the dark zones, $2 \mathrm{D}$, or between a light and dark zone, $D$, and knowing the initial spacing, $p$, would allow the calculation of the strain and radial growth that the disk was subject to during operation. To enhance the localized stress that the disk would experience during operation, a $50.8 \mathrm{~mm}$ ( 2 in.) long notch was machined into it to simulate a crack.

\section{Experimental Setup}

The subscale simulated turbine engine disk that was used in this experiment is shown in Figure 3 . The disk is $235 \mathrm{~mm}$ (9.25 in.) in diameter and has 32 evenly spaced blades. Its geometry is representative of that encountered in turbine engine disks. Its physical dimensions and characteristics are shown in Table 1. This disk has been well analyzed and used in previous fault detection experiments (Refs. 1 to 8) making it a good candidate for use with this experiment.

The notch and image pattern that was machined onto the disk is shown in Figure 4. The notch was machined into the disk prior to the experiment and was used for previous engine fault and crack detection experiments. The notch is located mid-span on the disk in the thinnest region. It is $50.8 \mathrm{~mm}(2.00 \mathrm{in}$.) long, $0.38 \mathrm{~mm}(0.15 \mathrm{in}$.) wide, and fully penetrates the disk with a depth of $2.54 \mathrm{~mm}(0.10 \mathrm{in}$.). The notch's purpose was to simulate a crack and enhance the localized stress and growth in the area around the crack. While considered large for realistic applications, it has served as an ideal test case in previous proof-of-concept fault and crack detection studies similar to the Moiré concept being investigated in this paper. The pattern that was applied to the disk in order to view the Moiré shift consisted of concentric circles that were $0.254 \mathrm{~mm}$ (0.010 in.) wide and uniformly spaced $0.254 \mathrm{~mm}(0.010 \mathrm{in}$.) apart. 


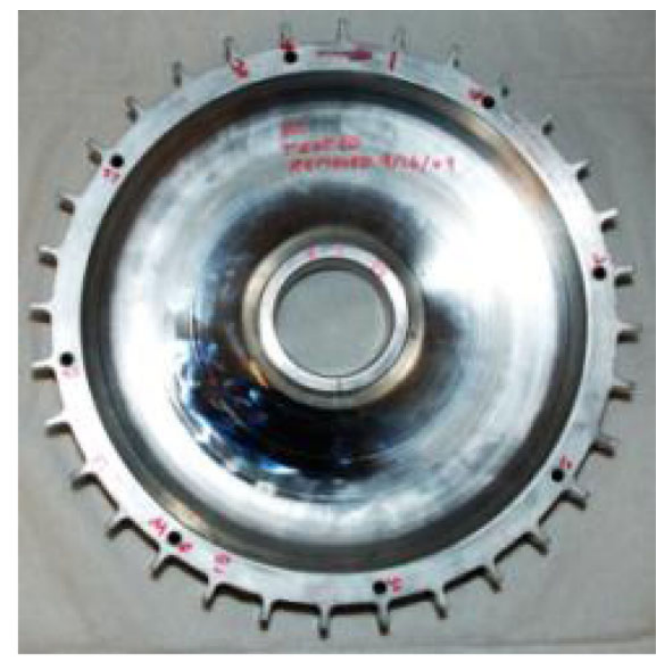

Figure 3.-Subscale engine disk.

TABLE 1.-PHYSICAL PROPERTIES OF SUBSCALE ENGINE DISK

\begin{tabular}{|l|l|}
\hline Material & Haynes-X-750 \\
\hline Diameter & $235 \mathrm{~mm}(9.25 \mathrm{in})$. \\
\hline Rim thickness & $31.75 \mathrm{~mm}(1.25 \mathrm{in})$. \\
\hline Bore thickness & $25.4 \mathrm{~mm}(1.00$ in. $)$ \\
\hline Web thickness & $2.54 \mathrm{~mm}(0.10$ in. $)$ \\
\hline Weight & $4.88 \mathrm{~kg}(10.75 \mathrm{lb})$ \\
\hline Blades & 32 blades each \\
& $31.75 \mathrm{~mm}(1.25$ in. $)$ wide by $3.30 \mathrm{~mm}$ \\
& $(0.125$ in. $)$ thick by $8.38 \mathrm{~mm}(0.333 \mathrm{in}$.$) high$ \\
\hline
\end{tabular}

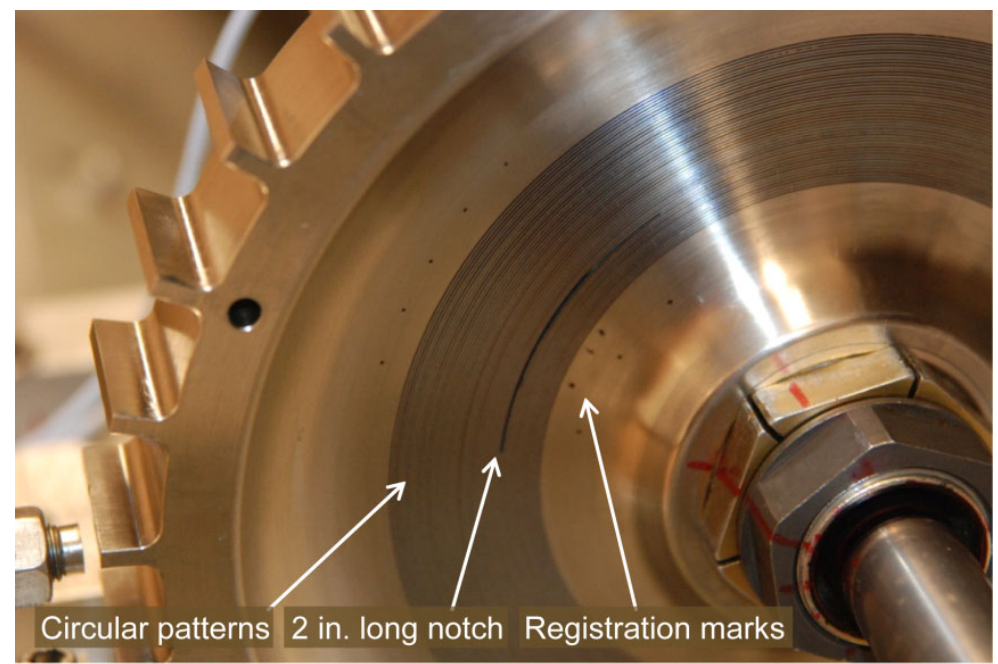

Figure 4.-Subscale engine disk with notch and pattern applied.

The pattern was machined on to the disk using a precision lathe. The circles were made just deep enough, $\sim 0.08 \mathrm{~mm}$ ( $\sim 3 \mathrm{mils})$, so that a material could be applied to the grooves to provide contrast when imaging. A blue dye used in machining applications was applied to the disk then lightly sanded off, leaving the dye in the grooves to provide the needed contrast for viewing the circular pattern. Registration marks were also added to the disk to facilitate the alignment of the images acquired statically and on-condition. One issue that was encountered with the application of the patterns is that, due to the curvature of the disk's surface, only the flat portion of the disk from a radius beginning at $47.2 \mathrm{~mm}$ (1.86 in.) and ending at 
$71.6 \mathrm{~mm}$ (2.82 in.) was able to have the circles applied as opposed to covering the desired hub-to-blade region of the disk, which began at the shaft and ended at a radius of $\sim 109 \mathrm{~mm}$ (4.275 in.). It was also intended for the circle width and spacing to be on the order of $0.13 \mathrm{~mm}(0.005 \mathrm{in}$.). However, this was not able to be done in a consistent manner using the precision machining method that was employed, and resulted in the use of the larger $0.254 \mathrm{~mm}(0.010 \mathrm{in}$.) width and spacing for the experiment. Both of these issues combined, limited the ability to observe the Moiré dark and light zones set up in the pattern. Even with these limitations, it was decided to still proceed with the test to see what could be seen and use it as a learning opportunity for further refining this technique for future tests.

The NASA Glenn Research Center's High Precision Spin Rig was used to operate the disk for this experiment. The High Precision Spin Rig is shown in Figure 5. The spin rig can accommodate simulated engine rotor disks of up to $235 \mathrm{~mm}$ (9.25 in.) in diameter. It has a stainless steel shaft with a length of $781 \mathrm{~mm}$ (30.75 in.) and diameter of $20 \mathrm{~mm}$ (0.79 in.). The shaft is supported by precision contact ball bearings on each end with adjustable dampers positioned along the length shaft. A custom $12 \mathrm{hp}$ motor is used to operate the spin rig at speeds up to $12000 \mathrm{rpm}$. The setup for the experiment is shown in Figure 6. A five (5) Megapixel miniature machine vision digital camera with a 12 and $25 \mathrm{~mm}$ lens was used to acquire images of the disk statically and when it was being operated at $12000 \mathrm{rpm}$. To capture the image of the disk as it was being spun a 10W white light emitting diode (LED) with pulsed power supply was used as a strobe. A laser $1 / \mathrm{rev}$ was used to precisely drive the strobe as a function of rotor location and speed. In-house designed and fabricated pulse delay and pulse width control circuitry was used to condition the $1 / \mathrm{rev}$ signal for control of the strobe. The pulse delay was varied in order to image different regions of the disk while it was spinning. The pulse width was adjusted to obtain the crispest image of the disk while it was on test condition. In addition to the optical instrumentation listed above, microwave and capacitive blade tip clearance (BTC) sensors were used to acquire blade tip clearance data. These sensors, shown in Figure 6 , were located $180^{\circ}$ across from each other on the disk. Two eddy current displacement sensors located $90^{\circ}$ apart on the shaft were used to measure shaft location. The purpose of using this additional instrumentation was to compare any radial growth observed optically using the Moiré principle with the radial growth measured by these external sensors. They were also used to further develop crack detection techniques associated with these technologies.

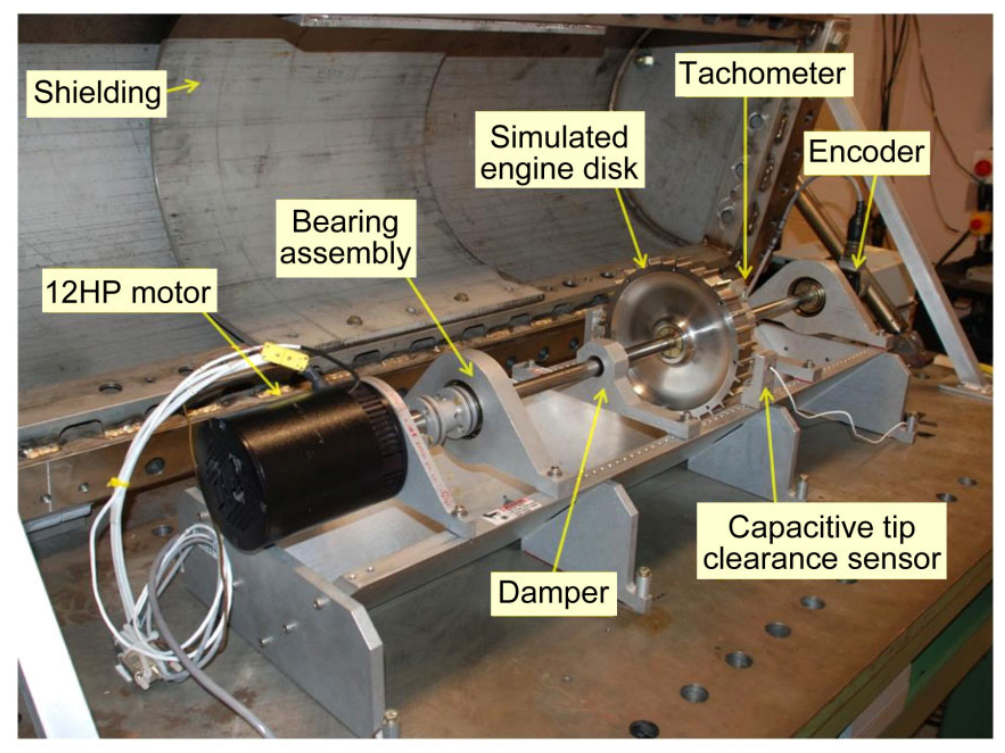

Figure 5.-High precision spin rig. 


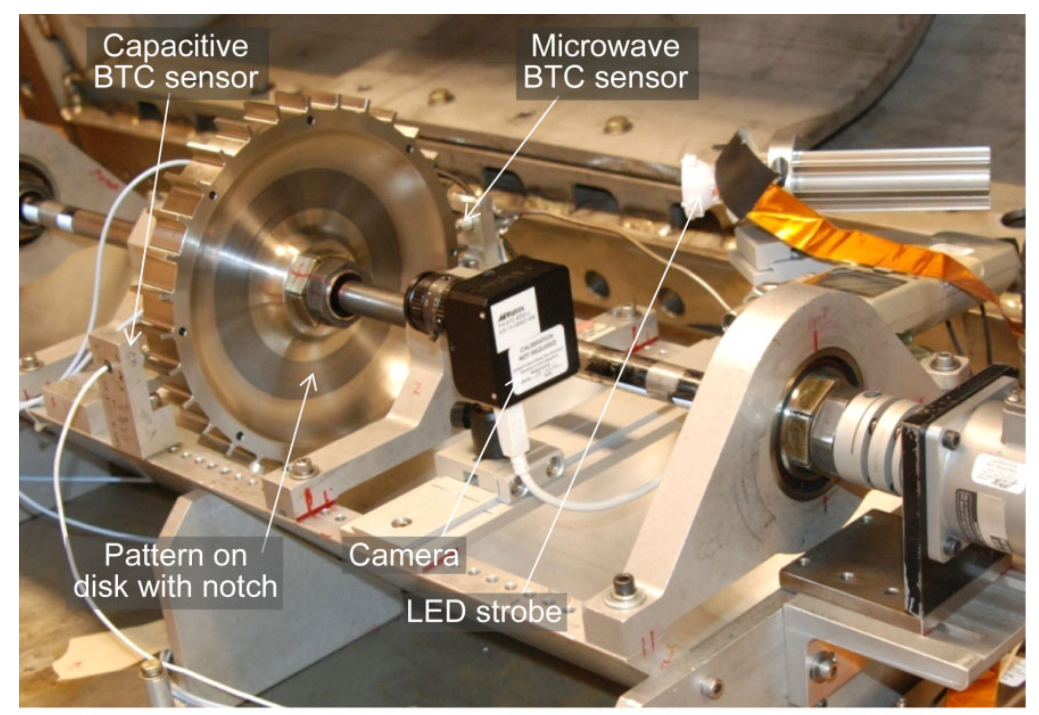

Figure 6.-Setup for Moiré crack detection experiment.

\section{Experimental Results}

\section{Optical Data}

As previously stated the methodology that was used to conduct the experiment was to acquire reference images of the disk at various locations at the static, 0 rpm condition, then spin the disk up to $12000 \mathrm{rpm}$ and acquire images of the disk at full speed operation in the same the locations that the reference images were acquired at. The two locations that were chosen were the region located by the notch and a clean, defect free region, located $180^{\circ}$ across from it. These were chosen as a means of viewing the radial growth associated with normal loading of the disk and the localized radial growth due to the simulated crack. The images were then post processed by first aligning them using the registration marks located on the inside radius of the disk and then overlaying the image that was acquired at $12000 \mathrm{rpm}$ onto the image that was taken statically. Imaging processing software was used to accomplish the sub-pixel alignment and overlay of the images. The composite image was then analyzed for the appearance of the Moiré light and dark zones due to the radial growth of the disk.

Figure 7 shows the images that were acquired for the clean, or baseline region, of the disk using a $12 \mathrm{~mm}$ lens. Figure 7(a) shows the reference image acquired at static conditions, Figure 7(b) shows the on-condition image acquired at $12000 \mathrm{rpm}$ and Figure 7(c) shows the resulting composite image obtained by overlaying the two images. For the baseline region of the disk the two images lined up exactly on top of each other and the light and dark zones due to the Moiré shift were not observed. Thus, indicating that very little radial growth was observed during high speed operation, which was expected for this side of the disk.

Figure 8 shows the images that were acquired for the region of the disk with the notch using a $12 \mathrm{~mm}$ lens. Figure 8(a) shows the reference image acquired at static conditions, Figure 8(b) shows the oncondition image acquired at $12000 \mathrm{rpm}$ and Figure 8(c) shows the resulting composite image obtained by overlaying the two images. Again, as previously observed the anticipated light and dark zones due to the Moiré shift were not observed. Thus, again, indicating that very little radial growth was optically observed. This was unexpected, as finite element analysis showed that up to a $\sim 0.075 \mathrm{~mm}(\sim 0.003 \mathrm{in}$. $)$ localized radial growth of the disk could be observed in the region of the notch under these loading conditions. The expectation was that at least the initiation of a pattern shift would be observable, especially in the rings beginning at the notch region and heading towards the outside edge of the disk. 

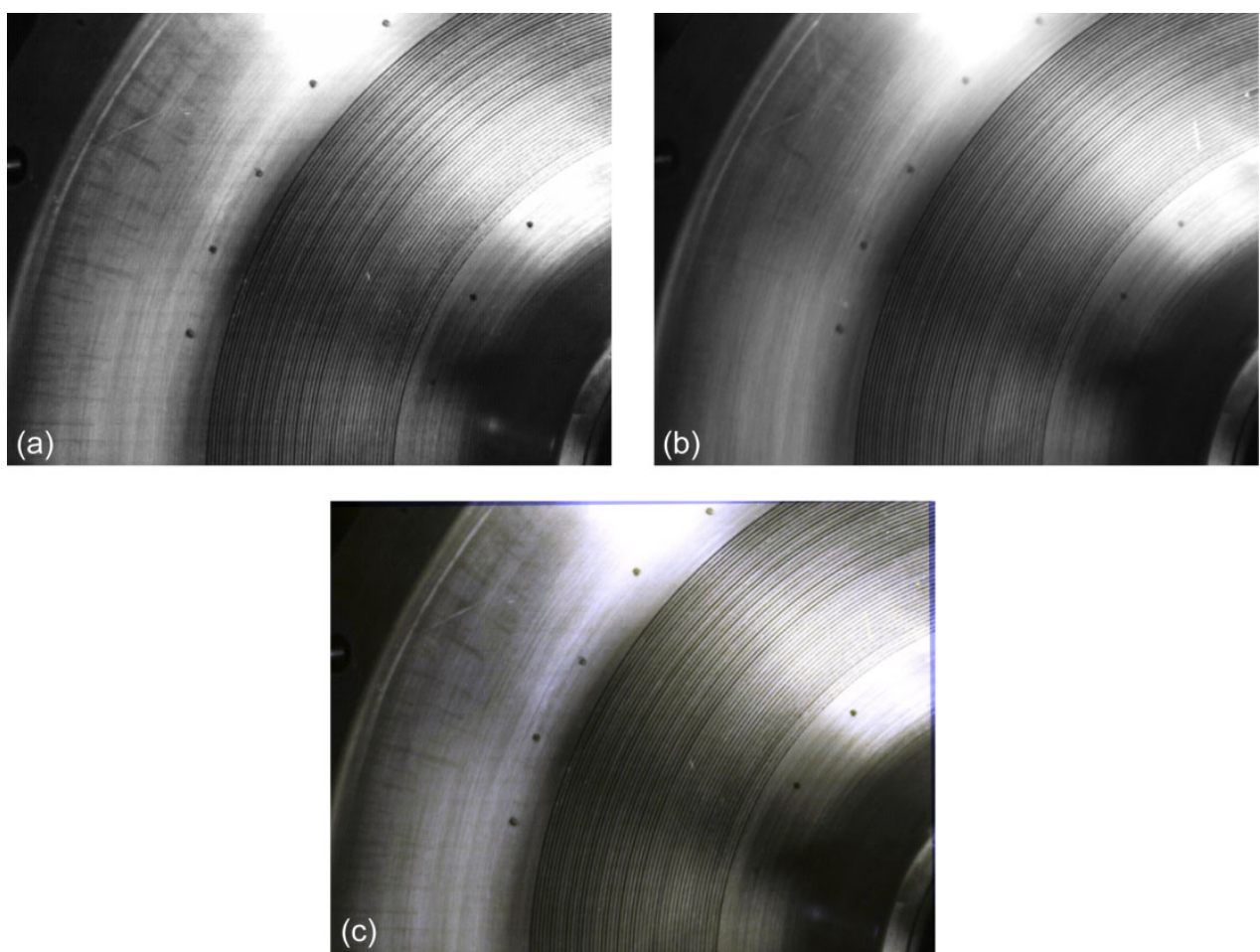

Figure 7.-Baseline region. (a) Static reference image. (b) On-condition image acquired at 12000 rpm. (c) Composite image.
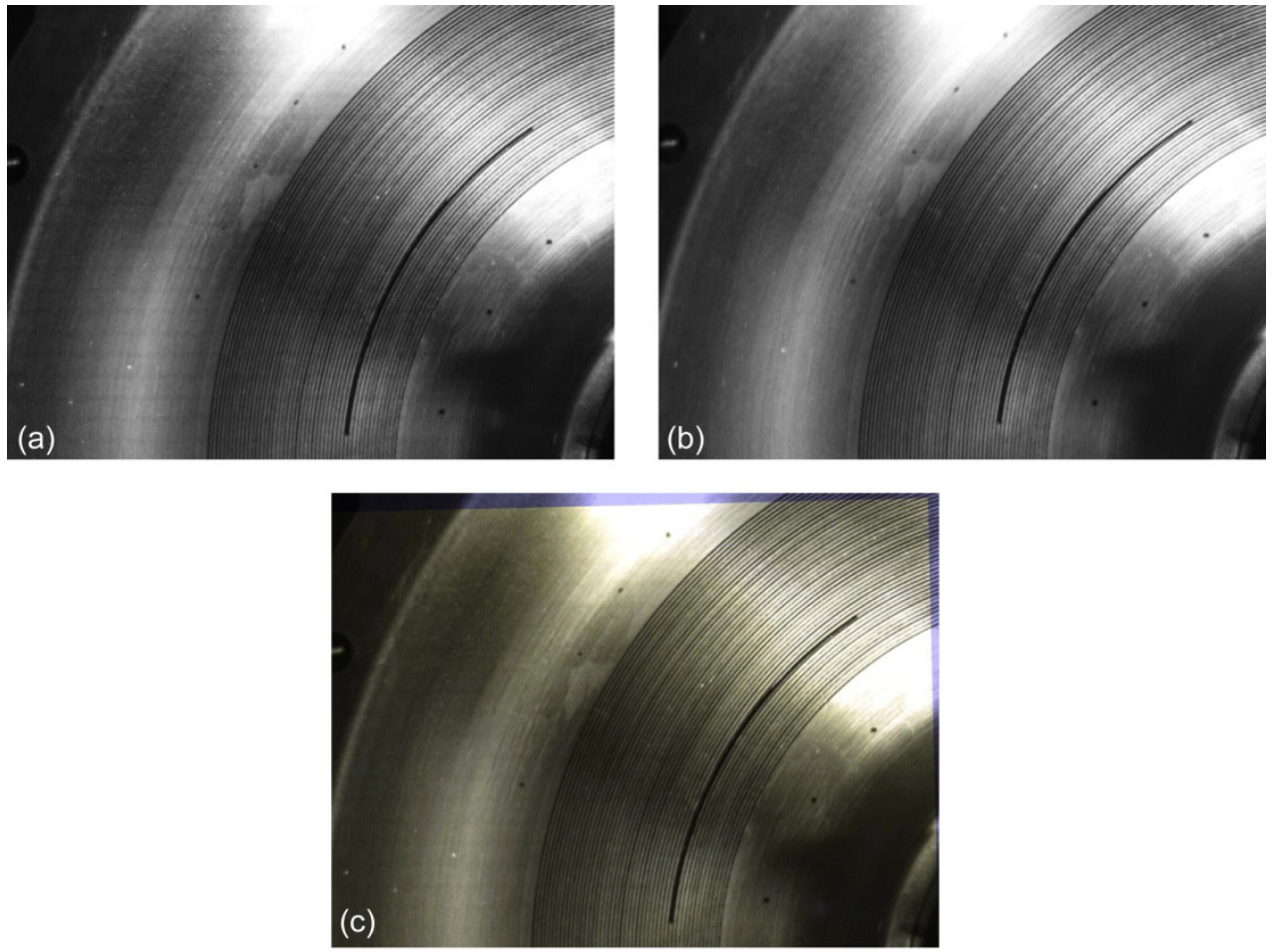

Figure 8.-Notch region. (a) Static reference image. (b) On-condition image acquired at 12000 rpm. (c) Composite image. 
To further investigate this concept a $25 \mathrm{~mm}$ lens was used in place of the $12 \mathrm{~mm}$ lens to magnify the region of interest. The same methodology was used to acquire images in both notch and baseline regions of the disk. The results from the notch region are presented in Figure 9. Figure 9(a) shows the reference image acquired at static conditions, Figure 9(b) shows the on-condition image acquired at $12000 \mathrm{rpm}$ and Figure 9(c) shows the resulting composite image obtained by overlaying the two images. As in the previous cases the anticipated shift due to any localized radial growth was not observable. The images lined up almost perfectly further verifying that the disk was experiencing very little if any growth due to the notch and the loads induced on it during operation. To further verify this observation a line intensity profile analysis was conducted over the last 10 rings on the composite image to determine if there was a shift due to radial growth of the disk as this would represent the best area to detect any radial growth. The region that was used for the intensity profile is indicated by the yellow line in Figure 9(c).

The intensity profile is shown in Figure 10. The green line indicates the intensity for the image that was acquired at $12000 \mathrm{rpm}$ and the blue line indicates the intensity of the static reference image. The valleys on the chart indicate the location of the grooves or dark lines of the pattern. The peaks indicate the space between the grooves or the light lines of the pattern. From visually analyzing the profile it is evident that the peaks and valleys of the intensity profiles match each other in the x-axis or radial direction on the disk. Again, this verifies that the disk experienced very little if any radial growth during operation.
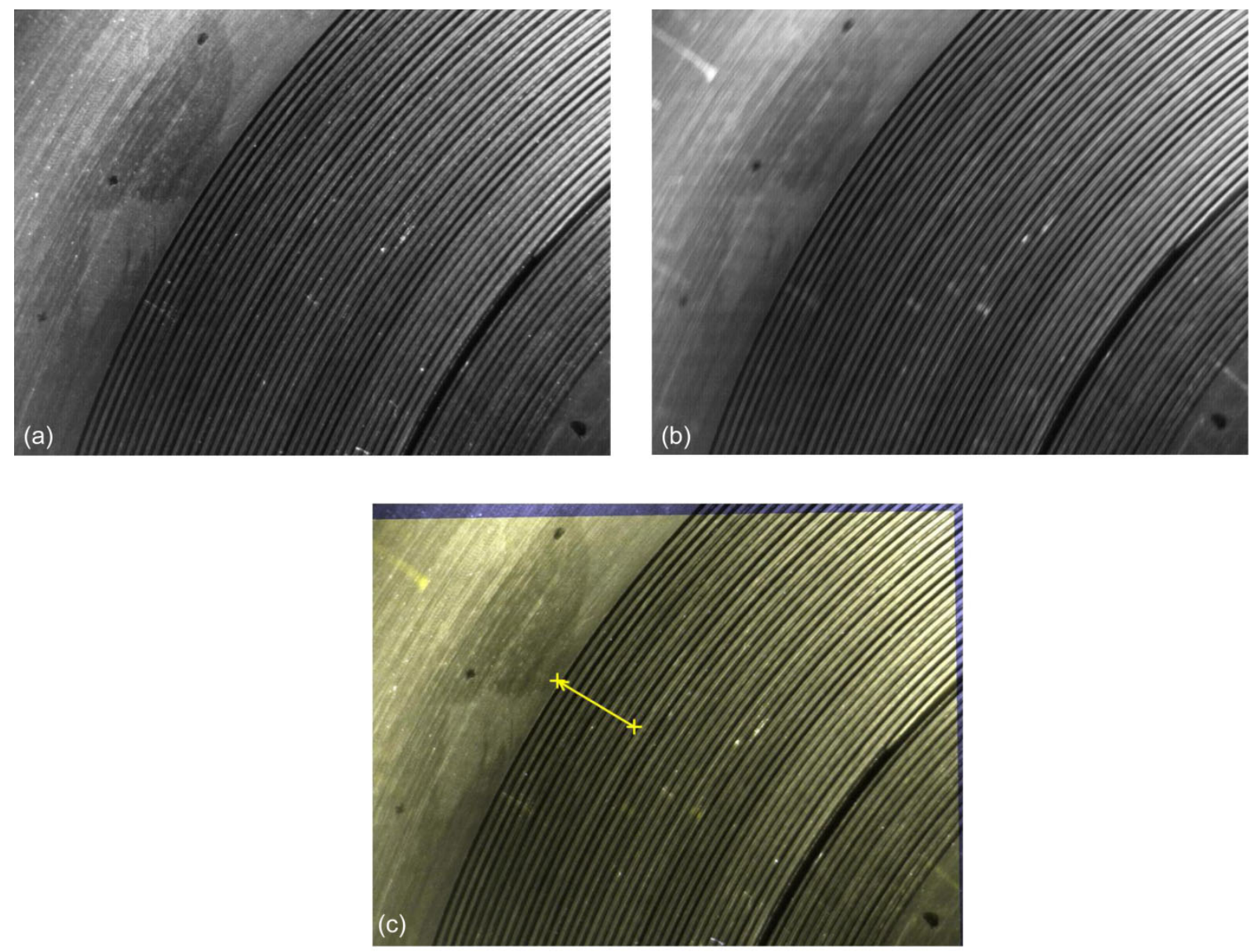

Figure 9.-Notch region with $25 \mathrm{~mm}$ lens. (a) Static reference image. (b) On-condition image acquired at 12000 rpm. (c) Composite image. 


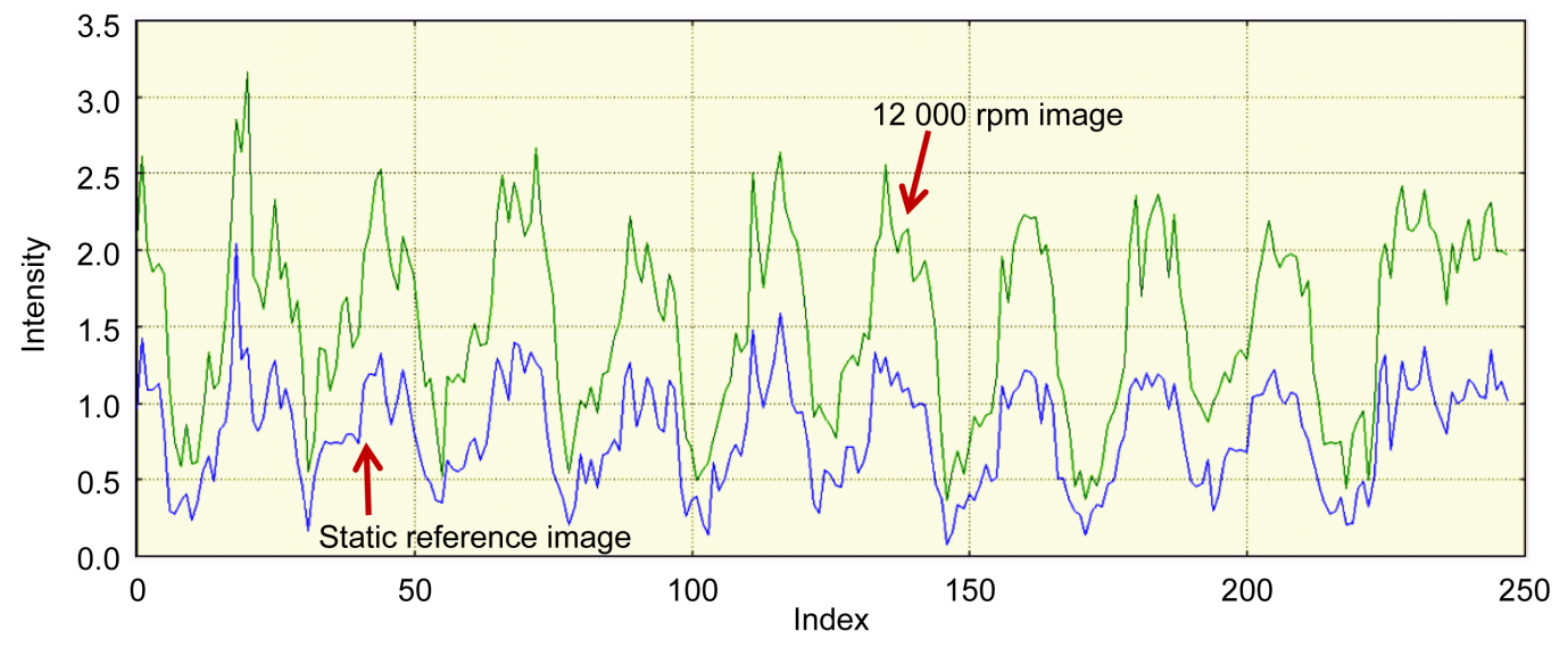

Figure 10.-Intensity profile.

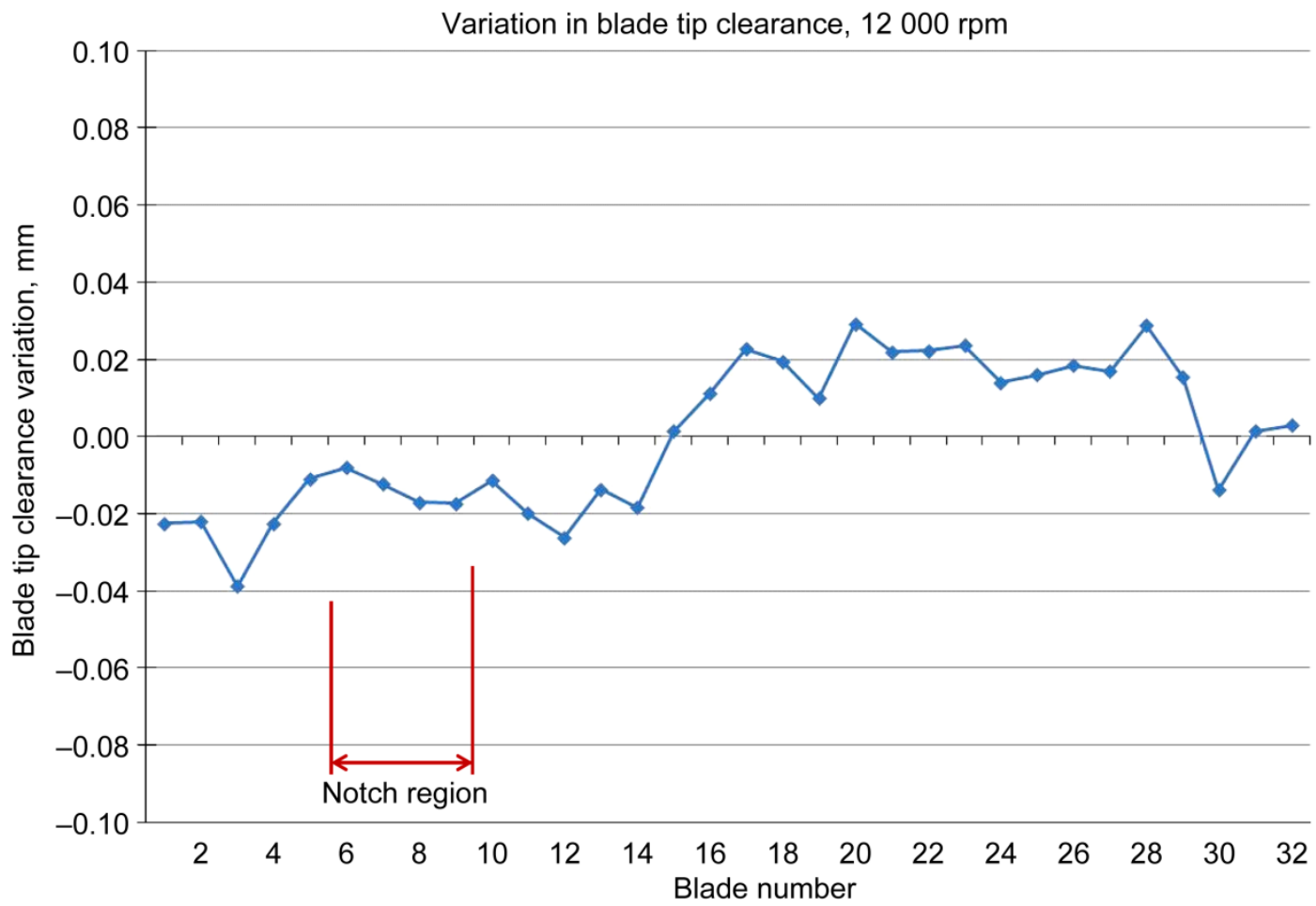

Figure 11.-Blade tip clearance profile.

\section{External Sensor Data}

As part of this experiment blade displacement data sets were acquired using external blade tip clearance and shaft displacement sensors for comparison to the data obtained from the optical technique. Both microwave and capacitive based blade tip clearance sensors were used to measure the disks vibration by monitoring the radial clearance for each blade and hence the radial growth of the disk. These sensors have been used in previous crack detection studies conducted in the spin lab (Refs. 11 and 12). The results measured by the microwave blade tip clearance sensor during this experiment are presented. The variation in blade tip clearance measured over 1 revolution, 32 blades, at a rotational speed of $12000 \mathrm{rpm}$ is shown in Figure 11. The red line indicates the region of the disk that contains the notch. From analyzing the graph a variation of $0.03 \mathrm{~mm}(0.001 \mathrm{in}$.) to $-0.04 \mathrm{~mm}(-0.0016 \mathrm{in}$.) is observed 
during operation of the disk. This minimal variation is thought by the authors to be due more to discrepancies in blade length and shaft wobble caused from Rotordynamics of the spin rig rather than radial growth of the disk. In previous experiments, up to $\pm 0.03 \mathrm{~mm}(0.001 \mathrm{in}$.) of shaft wobble has been measured at steady state operation using eddy current shaft displacement sensors. In addition, in the area of the notch, the blade tip clearance is observed to be stable or actual slightly increasing, which is counter to what would be expected if the disk experienced localized growth in this region. Hence, the external sensor data verified what was observed on the optical data regarding the minimal or lack of radial growth on the disk during operation.

\section{Conclusion and Future Plans}

This initial proof of concept experiment for the Moiré based crack detection scheme did not yield the expected results. The disk did not experience the localized radial growth that was expected in the notched area of the disk during operation. This finding was confirmed with both optical and external sensor data sets that were acquired during the experiment. The lack of detectable radial growth prevented the successful demonstration of the Moiré based crack detection technique. However, while not successful for this experiment, this Moiré based optical concept still has merit and this first attempt will be used as a learning opportunity to further refine and validate this concept. Some of the lessons learned that will be applied to future experiments are as follows.

First, the Finite Element Analysis model that was originally used to investigate the disk will be re-evaluated and adjusted based on the results of the experiment. The original model showed that up to $\sim 0.075 \mathrm{~mm}$ ( $\sim 0.003 \mathrm{in}$.) of localized growth would be experienced in the notched region of the disk. Experimental results actually showed the overall radial growth of the disk to be well under $\sim 0.025 \mathrm{~mm}$ ( $\sim 0.001 \mathrm{in}$.), and in reality probably closer to zero. The modeling will be improved to better predict the growth, so the proper disk size, disk material, notch size and Moiré pattern spacing and width can be selected to better demonstrate the concept in future experiments. In addition, alternate methods of introducing a notch or defect to the disk will be investigated in order to get the desired radial growth.

The second major issue that was experienced during this investigation was the spacing of the image pattern and the limited area that it could be applied to the disk. Machining the pattern on to the disk limited the width and spacing to $0.254 \mathrm{~mm}(0.010 \mathrm{in}$.). The larger this spacing $(p)$, the longer the distance $(D)$, is between the light and dark zones for a given radial growth $(\Delta p)$, thus making the technique less sensitive to detect small changes. In addition to spacing, the area of the disk that was covered by the pattern was limited by the machining method that was used to apply the pattern due to the curved geometry of the disk's surface. Thus, only the flat portion of the disk beginning at radius of $47.2 \mathrm{~mm}$ (1.86 in.) and ending at a radius of $71.6 \mathrm{~mm}$ (2.82 in.) was able to have the circles applied as opposed to covering the full radius of $\sim 109 \mathrm{~mm}$ (4.275 in.). This limited the area that could be used to observe the pattern shift due to and set up of the light and dark zones due to radial growth. To remedy both of these shortcomings, alternate methods of applying the pattern such as photolithography or laser etching along with the use of alternate Moiré patterns will be investigated in order to get wider coverage, closer spacing and better sensitivity for future experiments.

The last issue that will be addressed was the imaging of the disk during operation. As discussed previously, in order to capture an image of the disk operating at $12000 \mathrm{rpm}$ a $10 \mathrm{~W}$ white light emitting diode (LED) was used as a strobe. For the most part this technique worked and we were able to successfully acquire the images and develop the processing routines required to compare the reference and on-condition image pairs. However, one shortcoming was the inability to get the proper lighting coverage of the disk during acquisition. During testing the lighting power and location had to be adjusted several times to get a crisp image. Even then the coverage was not as uniform as desired and both hot and dark spots were encountered making processing the images difficult. The hot spots were due to the high reflectivity of the disk which required the LED to be moved to an area where it indirectly lighted the region of interest on the disk. This in turn created dark spots that were mostly due to shadows cast by the shaft and other test rig components that were between the LED and disk. This lack of uniform lighting 
made processing the images difficult. To remediate this for future experiments options such as applying a non-reflective coating on the disk and the use of additional LEDs will be pursued in order to provide better lighting coverage of the disk. In addition, the use of shorter duration pulses will be employed to cut down on the image smearing encountered at the high rotational speeds.

These improvements are in the process of being incorporated for the next phase of experimentation that is being planned to demonstrate this Moiré based crack detection technique. For the next test it is planned to manufacture a sub-scale turbine engine disk made out of aluminum. This softer material will experience greater radial growth during operation and better lend itself to demonstrating the concept. This disk will also have a notch machined into it to simulate a crack and of a sufficient size to induce localized radial growth. In addition, it is intended to apply patterns over the entire area of the disk with a closer spacing to increase sensitivity. On-board strain sensors and external blade tip clearance instrumentation will also be used to monitor disk strain and radial growth for comparison to the optical data. If this proof of concept test is successful, the techniques will be further refined for use on more realistic disk geometries and materials. The results of this planned experimentation will be reported in future papers.

\section{References}

1. Woike, M.R., Abdul-Aziz, A., "Crack-Detection Experiments on Simulated Turbine Engine Disks in NASA Glenn Research Center's Rotordynamics Laboratory,” NASA/TM-2010-216239, 2010.

2. Abdul-Aziz, A., Woike, M.R., Oza, N., Matthews, B. and Baaklini, G.Y., "Propulsion Health Monitoring of a Turbine Engine Disk Using Spin Test Data," NASA/TM-2010-216743, 2010.

3. Abdul-Aziz, A., Woike, M.R., Lekki, J.D., and Baaklini, G.Y., "Health Monitoring of a Rotating Disk Using a Combined Analytical-Experimental Approach," NASA/TM-2009-215675, 2009.

4. Abdul-Aziz, A., Woike, M.R., Lekki, J.D., and Baaklini, G.Y., "NDE Using Sensor Based Approach to Propulsion Health Monitoring of a Turbine Engine Disk," SPIE's 16th Annual International Symposium on Nondestructive Evaluation for Health Monitoring and Diagnostics, San Diego, CA, Mar. 9-12, 2009.

5. Abdul-Aziz, A., Trudell, J.J., and Baaklini, G.Y., "Finite Element Design Study of a Bladed, Flat Rotating Disk to Simulate Cracking in a Typical Turbine Disk; Part II," SPIE's 11th Annual International Symposium on Nondestructive Evaluation for Health Monitoring and Diagnostics, SPIE, San Diego, CA, Feb. 26-Mar. 2, 2006.

6. Abdul-Aziz, A., Trudell, J.J., and Baaklini, G.Y., "Finite Element Design Study of a Bladed, Flat Rotating Disk to Simulate Cracking in a Typical Turbine Disk," SPIE's 10th International Symposium on Nondestructive Evaluation for Health Monitoring and Diagnostics, San Diego, CA, Mar. 6-10, 2005.

7. Gyekenyesi, A.L., Sawicki, J.T., and Baaklini, G.Y., "Vibration Based Crack Detection in a Rotating Disk, Part 1-An Analytical Study,” NASA/TM-2003-212624, 2003.

8. Gyekenyesi, A.L., Sawicki, J.T., Martin, R.E., Haase, W.C., and Baaklini, G.Y., "Vibration Based Crack Detection in a Rotating Disk, Part 2 - Experimental Results," NASA/TM-2005212624/PART2, 2005.

9. Oster, G., Nishijima, Y., "Moire Patterns," Scientific American, p54-63, 1963.

10. http://switzernet.com/people/emin-gabrielyan/070306-optical-speedup/\# Toc160944479

11. Woike, M.R., Abdul-Aziz, A., Bencic, T.J., "A Microwave Blade Tip Clearance Sensor for Propulsion Health Monitoring," NASA/TM-2010-216736, 2010.

12. Woike, M.R., Roeder, J.W., Hughes, C.E., Bencic, T.J., "Testing of a Microwave Blade Clearance Sensor at the NASA Glenn Research Center," NASA/TM-2010-216736, 2010. 


\begin{tabular}{|c|c|c|}
\hline \multicolumn{2}{|c|}{ REPORT DOCUMENTATION PAGE } & $\begin{array}{l}\text { Form Approved } \\
\text { OMB No. 0704-0188 }\end{array}$ \\
\hline \multicolumn{3}{|c|}{ 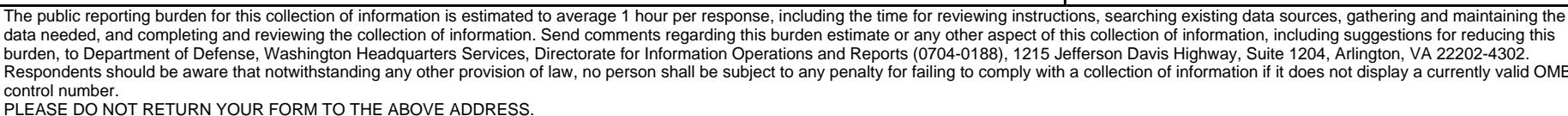 } \\
\hline $\begin{array}{l}\text { 1. REPORT DATE (DD-MM-YYYY) } \\
01-06-2012\end{array}$ & $\begin{array}{l}\text { 2. REPORT TYPE } \\
\text { Technical Memorandum }\end{array}$ & 3. DATES COVERED (From - To) \\
\hline \multirow{3}{*}{\multicolumn{2}{|c|}{$\begin{array}{l}\text { 4. TITLE AND SUBTITLE } \\
\text { Investigation of a Moiré Based Crack Detection Technique for Prop }\end{array}$}} & 5a. CONTRACT NUMBER \\
\hline & & 5b. GRANT NUMBER \\
\hline & & 5c. PROGRAM ELEMENT NUMBER \\
\hline \multirow{3}{*}{\multicolumn{2}{|c|}{$\begin{array}{l}\text { 6. AUTHOR(S) } \\
\text { Woike, Mark, R.; Abdul-Aziz, Ali; Fralick, Gustave, C.; Wrbanek, }\end{array}$}} & 5d. PROJECT NUMBER \\
\hline & & 5e. TASK NUMBER \\
\hline & & $\begin{array}{l}\text { 5f. WORK UNIT NUMBER } \\
\text { WBS 284848.02.03.03.02.01 }\end{array}$ \\
\hline \multicolumn{2}{|c|}{$\begin{array}{l}\text { 7. PERFORMING ORGANIZATION NAME(S) AND ADDRESS(ES) } \\
\text { National Aeronautics and Space Administration } \\
\text { John H. Glenn Research Center at Lewis Field } \\
\text { Cleveland, Ohio 44135-3191 }\end{array}$} & $\begin{array}{l}\text { 8. PERFORMING ORGANIZATION } \\
\text { REPORT NUMBER } \\
\text { E-18210 }\end{array}$ \\
\hline \multirow{2}{*}{\multicolumn{2}{|c|}{$\begin{array}{l}\text { 9. SPONSORING/MONITORING AGENCY NAME(S) AND ADDRESS(ES) } \\
\text { National Aeronautics and Space Administration } \\
\text { Washington, DC 20546-0001 }\end{array}$}} & $\begin{array}{l}\text { 10. SPONSORING/MONITOR'S } \\
\text { ACRONYM(S) } \\
\text { NASA }\end{array}$ \\
\hline & & $\begin{array}{l}\text { 11. SPONSORING/MONITORING } \\
\text { REPORT NUMBER } \\
\text { NASA/TM-2012-217622 }\end{array}$ \\
\hline \multicolumn{3}{|c|}{$\begin{array}{l}\text { 12. DISTRIBUTION/AVAILABILITY STATEMENT } \\
\text { Unclassified-Unlimited } \\
\text { Subject Categories: } 33,35 \text {, and } 07 \\
\text { Available electronically at http://www.sti.nasa.gov } \\
\text { This publication is available from the NASA Center for AeroSpace Information, 443-757-5802 }\end{array}$} \\
\hline
\end{tabular}

\section{SUPPLEMENTARY NOTES}

\section{ABSTRACT}

The development of techniques for the health monitoring of the rotating components in gas turbine engines is of major interest to NASA's Aviation Safety Program. As part of this on-going effort several experiments utilizing a novel optical Moiré based concept along with external blade tip clearance and shaft displacement instrumentation were conducted on a simulated turbine engine disk as a means of demonstrating a potential optical crack detection technique. A Moiré pattern results from the overlap of two repetitive patterns with slightly different periods. With this technique, it is possible to detect very small differences in spacing and hence radial growth in a rotating disk due to a flaw such as a crack. The experiment involved etching a circular reference pattern on a subscale engine disk that had a $50.8 \mathrm{~mm}$ ( 2 in.) long notch machined into it to simulate a crack. The disk was operated at speeds up to $12000 \mathrm{rpm}$ and the Moiré pattern due to the shift with respect to the reference pattern was monitored as a means of detecting the radial growth of the disk due to the defect. In addition, blade displacement data were acquired using external blade tip clearance and shaft displacement sensors as a means of confirming the data obtained from the optical technique. The results of the crack detection experiments and its associated analysis are presented in this paper.

\section{SUBJECT TERMS}

Gas turbine engines; IVHM; Blade tip clearance; Aeropropulsion

\begin{tabular}{|c|c|c|c|c|c|}
\hline \multicolumn{3}{|c|}{ 16. SECURITY CLASSIFICATION OF: } & \multirow{2}{*}{$\begin{array}{l}\text { 17. LIMITATION OF } \\
\text { ABSTRACT } \\
\text { UU }\end{array}$} & \multirow{2}{*}{$\begin{array}{l}\text { 18. NUMBER } \\
\text { OF } \\
\text { PAGES } \\
18\end{array}$} & \multirow{2}{*}{$\begin{array}{l}\text { 19a. NAME OF RESPONSIBLE PERSON } \\
\text { STI Help Desk (email:help@sti.nasa.gov) } \\
\text { 19b. TELEPHONE NUMBER (include area code) } \\
\text { 443-757-5802 }\end{array}$} \\
\hline $\begin{array}{l}\text { a. REPORT } \\
U\end{array}$ & $\begin{array}{l}\text { b. ABSTRACT } \\
U\end{array}$ & $\begin{array}{l}\text { c. THIS } \\
\text { PAGE } \\
\text { U }\end{array}$ & & & \\
\hline
\end{tabular}


